\title{
A FLAW IN THE THROWBACK RULES FOR CAPITAL GAIN DISTRIBUTIONS
}

\author{
RICHARD D. HOBBET*
}

When Congress changed the accumulation trust rules in the Tax Reform Act of 1969 they made it clear that they intended to make the throwback rules for undistributed net income of trusts equally applicable to capital gains accumulated and added to corpus for all complex trusts after the first year in which they accumulated any income. But, because of an apparent flaw in drafting the provisions, it is conjectural that Congress has accomplished its purpose. Indeed, it may be that as the statute now stands, it is nothing more than a trap for an occasional mistake made by an unknowing trustee. The explanation for this will involve us in the intricacies of several complex new Internal Revenue Code provisions in Subpart D of Subchapter $\mathrm{J}$ of the Code. ${ }^{1}$

Our task will be easier if we use an example. To keep it relatively simple, assume that a trust, created on January 1, 1969, has income of $\$ 2,000$ and capital gains of $\$ 5,000$ for each of two years, 1969 and 1970 . In each year the trust pays income taxes of $\$ 225$ which are attributable to the income and $\$ 570$ attributable to the capital gains. The income in excess of taxes is accumulated and the balance of capital gains is allocated to corpus and accumulated. The distributable net income (DNI) for each year is $\$ 2,000$. In the next year, 1971, assume that the trust has no income and no capital gains or losses and that it distributes $\$ 10,000$ to its one beneficiary.

The treatment of the distribution with respect to the accumulated income is straightforward enough under present law and does not differ in this example from preexisting law, but it will help to describe the statute's treatment of it. For each of the years 1969 and 1970 the trust is considered to have undistributed net income (UN1) under section 665 of $\$ 1,775$, being the excess of the DNI for each year $(\$ 2,000)$ over the section 661 (a) amounts (zero) and the taxes imposed on the trust which are attributable to the DNI (\$225).

It will be of some purpose to note that the UNI is an amount computed for each year and it is not a cumulative sum of the UNI for all of the years of the trust. Were it a cumulative sum, then the UNI

* Professor of Law, Duke University School of Law. B.A. 1949, J.D. 1951, University of lowa. Corporations Editor. Journal of TAXation; Associate Editor, The TAX LAwyer.

1. 26 U.S.C. $\S \S 665-69$ (Supp. V, 1970). 
for the year 1970 would be the sum of the UNI for 1969 and 1970, or $\$ 3,550$.

In 1971 , the above trust has made an accumulation distribution (AD) of $\$ 10,000$, being the excess of the section $661(a)(2)$ distributions for the year $1971(\$ 10,000)$ over the DNI (zero) reduced by the section $66 \mathrm{I}(\mathrm{a})(\mathrm{l})$ distributions (zero). Under section 666 it is clear that the AD for 1971 is thrown back and treated as a distribution of the UN1 for each of the years 1969 and 1970. It is deemed to be a section 66l(a)(2) distribution as of the last day of the year of each of such years to the extent it "exceeds the total of any undistributed net income for all earlier preceding taxable years." In this case there is no UNI for any year preceding 1969 and there is $\$ 1,775$ of UNI for "all earlier preceding taxable years" with respect to the year 1970. Thus, there is ample AD for each of such years and the second sentence of 666(a) is therefore the limiting factor, stating that the amount deemed distributed in each year shall not exceed the UNI for that year. Therefore, $\$ 1,775$ is deemed distributed in each such year. The taxes attributable to such UNI are also deemed distributed pursuant to section $666(\mathrm{~b})$.

With $\$ 3,550$ of the AD for 1971 thus used up as a distribution of prior years' UNI, it was the clear intent of Congress that the balance of the distribution $(\$ 6,450)$ be treated as a distribution of the accumulated capital gains in the prior years. In reporting its bill, the Finance Committee said that it had modified the House bill "to treat those capital gains of accumulation trusts allocated to the corpus of the trust in a manner similar to ordinary income accumulations."'2 It further explained this change as providing "an unlimited throwback rule for capital gains allocated to the corpus of an accumulation trust."' And if any doubt remained it added, "[f]or purposes of this provision, a capital gains distribution will be deemed to have been made only when the distribution is greater than all of the accumulated ordinary income. If the trust has no accumulated ordinary income or capital gains, or if the distribution is greater than the ordinary income or capital gain accumulations, then to this extent it will be considered a distribution of corpus and no additional tax will be imposed."'

The method the statute adopts to accomplish this result is

2. Se.vate Comm. on Finance. Tax Reform Act of 1969, S. Rep. No. 552.91st Cong., Ist Sess. 127 (1969).

3. Id. at 130 .

4. Id. (emphasis added). 
predictably similar to the rules relating to distributions of UNI. In section $665(\mathrm{f})$ undistributed capital gains (UCG) are defined and in $665(\mathrm{~g})$ a capital gain distribution (CGD) is defined. Finally, section 669 prescribes throwback rules for a CGD and the method of cooputing the tax on such CGD. The UCG defined in $665(f)$ is basically the excess of net capital gains which are not included in DNI over the taxes imposed on the trust attributable to such gains. In our example, this would be $\$ 4,430$ for the year 1969. However, the statute raises the interpretative problem of whether UCG is a cumulative amount so that the 1970 UCG would be the sum of undistributed gains for the years 1969 and 1970 , thus $\$ 8,860$, or an amount computed only with respect to the year 1970, in which event the UCG for 1970 would be the same as it was in $1969, \$ 4,430$. The question assumes great importance when one proceeds to the definition of CGD in section $665(\mathrm{~g})$, but it is presented in section $665(\mathrm{f})$ by a slight difference in the form of the definition of UCG from the 665(a) definition of UNI. Section 665(a) clearly specifies that the UNI for any particular taxable year is the excess of the DNI of the trust "for such taxable year" over certain distributions and taxes. Section 665(f) omits the quoted phrase. It does not clearly provide that it speaks of "gains in excess of losses from the sale or exchange of capital assets" for such taxable year even though it seems to imply such an interpretation in defining UCG "for any taxable year of the trust."

The importance of the distinction is made clear in section $665(\mathrm{~g})$ which defines the amount of the CGD which is to be thrown back to earlier years under section 669 . In section $665(\mathrm{~g})$ such capital gain distribution for any taxable year of the trust appears to be limited to the "undistributed capital gain for such taxable year." Since there are no capital gains or losses in the year 1971, when the CGD is made, the limitation would be zero and it would prevent any amount from being considered a capital gains distribution for the year 1971 if there is no CGD for that year. The throwback rules of section 669 would not permit any additional tax to be imposed on the beneficiary for the year 1971 as a result of the apparent distribution of the accumulated capital gains of earlier years.

To avoid this result, one is tempted to interpret the phrase "undistributed capital gain for such taxable year," as used in section $665(\mathrm{~g})$ as meaning a cumulative amount of all UCG for all preceding taxable years. In that case, at least for purposes of section $665(\mathrm{~g})$, the UCG for the year 1971 would be the sum of the UCG of all three of 
the years 1969 to 1971 , or $\$ 8,860$. This amount would be the limitation and we would then need to consider the rest of the definition, which describes the CGD as the excess of the AD for the year 1971 over the UNI of the trust for all preceding taxable years. In our example this would be $\$ 10,000$ minus $\$ 3,550$, or $\$ 6,450$. Of that amount, $\$ 4,430$ would be deemed a distribution of the capital gain in 1969 and $\$ 2,020$ would be deemed a distribution of capital gains in the year 1970. There are serious difficulties presented by Subpart $D^{5}$ to this interpretation, and these will be explained, but first it will be useful to see what tax planners might accomplish by way of avoiding the congressional intent should the interpretation of UCG as a cumulative amount be rejected.

If the amounts to be thrown back and considered capital gain distributions in earlier years are restricted to the undistributed capital gains of the year in which the distribution is made, it is clear that the capital gains accumulated by a trust can be distributed with impunity in any year in which the trust has no capital gains. Thus, in our example, the trustee, by waiting until a year in which the trust has no capital gains, is able to distribute some or all of the gains accumulated in earlier years without causing the beneficiary to incur any tax under the throwback rules. Furthermore, if the trust in fact had capital gains for the year 1971, the trustee could still avoid the impact of the throwback rules by making a discretionary distribution of the capital gains for the current year so that there would be no undistributed capital gains for the year 1971, and then make the distribution of the earlier accumulations of capital gains. Only if the trustee made the mistake of accumulating current gains and distributing prior accumulations of capital gains, would the beneficiary incur a tax on distributions of capital gains deemed to have been made in earlier years under the throwback rules. Congress surely did not intend this result and yet the statute's plain language appears to require such a result.

As has been shown, to avoid that result it is necessary to read "undistributed capital gain for such taxable year" as that phrase is used in section $665(\mathrm{~g})$ as meaning the accumulation of all capital gains not included in DNI in all years after December 31, 1968.

The Commissioner has recently amended his regulations under section 665 by adding a new section $1.665(\mathrm{~g})-1$ to take that position,

5. 26 U.S.C. $\$ \S 665-69$ (Supp. V, 1970). 
stating that for purposes of section $665(\mathrm{~g})$ "undistributed capital gains" means the total of all undistributed capital gains for all years of the trust beginning after December $31,1968 .{ }^{6}$ In stating this, the Commissioner simply omits from his paraphrase of the statute the words "for such taxable year." Thus, he converts the phrase "undistributed capital gains for such taxable year," as it appears in the statute, to the phrase "undistributed capital gains." With the omission of those key words, the statute is easily interpreted in accordance with congressional intent. But with the offending words in the statute such an interpretation is totally at odds with the use of that term in section 669 as well as the apparent definition of the term in section $665(f)$. The throwback rules for capital gains which are provided in section 669 follow very closely the rules in section 666 for throwback of distributions of ordinary income amounts. Just as section 666 refers to UNI as a computed amount for each preceding taxable year, and not as a cumulative amount, section 669 refers similarly to UCG as an amount computed for each preceding taxable year and not as an amount accumulated from all preceding taxable years.

This is true of the first sentence of section 669(a) where it refers to the UCG "for all earlier preceding taxable years." If the UCG for any taxable year was a cumulative amount for all preceding years this would be a redundancy in the statute which would, by its plain meaning, require the capital gains of earlier years to be added into such total more than once. In our example, if UCG is a cumulative amount, then the UCG for the year 1969 was $\$ 4,430$ and the UCG for the year 1970 was $\$ 8,860$ and the UCG for all years prior to 1971 would be the sum of such amounts $(\$ 13,290)$, plainly a ridiculous interpretation.

It is also true of the second sentence of section 669(a) where the amount deemed distributed for any particular year is clearly limited to the UCG computed by reference only to the capital gains and losses for that particular year. To construe UCG as a cumulative amount in our example, the limitation of the second sentence of section 669(a) would impose a limit on the 1970 amount of capital gains deemed distributed to $\$ 8,840$, more than the actual capital gains accumulated

6. Treas. Reg. $\S 1.665(\mathrm{~g})$-I, T.D. 7080, 1971 INT. Rev. BuLl. No. 2, at 9. On February 9 , 1971, the Commissioner issued notice of proposed amendments to this recently adopted regulation. 36 Fed. Reg. 2607, 2614. Although the wording is somewhat changed, and an example is added, there is no particular significance in the change to this discussion. 
that year. The statute clearly does not contemplate such an interpretation. But these are only two examples. Elsewhere in the statute it is also apparent that the term UCG is not used in such a way as to permit this interpretation.

Thus, one is faced with a plain dilemma. To reach the stated purpose of Congress one must read the phrase "undistributed capital gain for such taxable year" as it appears in section $665(\mathrm{~g})$ as having an entirely different meaning than essentially the same phrase means in other provisions of Subpart D. ${ }^{7}$ In section $665(\mathrm{~g})$ it must be construed as being a cumulative amount of the UCG for the current year and all preceding taxable years. But the same phrase must be read as meaning the annual amount for any particular year in every other place in the statute. With the statute also containing a precise definition of the term "undistributed capital gain" in section 665(f) such a reading is obviously going to require a farfetched flight of interpretative fancy. But to do otherwise is to concede that Congress failed to write the law it intended to write. For the courageous, this creates the opportunity to continue to use complex as well as simple trusts for accumulating capital gains for ultimate distribution without being subject to tax under the throwback rules of Subpart D.

7. 26 U.S.C. $\S \S 665-69$ (Supp. V, 1970). 